\title{
Experimentações rebeldes e novas estéticas de luta no contemporâneo
}

\author{
Rebel experiments and new aesthetics of struggle in the contemporary
}

Fernando Pinheiro Schubert; Ana Lúcia Coelho Heckert

Universidade Federal do Espírito Santo

\section{RESUMO:}

Este artigo apresenta um recorte das questões debatidas na dissertação de mestrado "Práticas de militância nômade: experimentações rebeldes e novas estéticas de luta no contemporâneo". Utilizando-se da experiência de um dos autores no processo de luta pela terra dos povos indígenas Tupinikim-Guarani no Estado do Espírito Santo (20052010), o texto objetiva analisar a constituição de formas de resistência problematizadoras das relações de poder instituídas na atualidade. $\mathrm{O}$ ato de retomada da terra empreendido por essas etnias e os efeitos que se seguiram na produção e articulação de ações rebeldes são debatidos em meio às fissuras que provocaram nos modos de funcionamento político que tecem a máquina administrativa do Estado, bem como dos próprios movimentos sociais. A emergência de dinâmicas e estéticas de luta dissidentes se expressa nos afrontamentos entre redes de insurgência e contrainsurgência, servindo como analisadores de uma sociedade mundial de controle espraiada por todo o tecido social.

Palavras-chave: movimentos sociais; militância; resistências.

\begin{abstract}
:
This article presents a clipping of the issues debated in the master's dissertation: "Practices of nomadic militancy: rebel experiments and new aesthetics of struggle in the contemporary". Using the experience of one of the authors in the process of TupinikimGuarani indigenous peoples' struggle for land in the State of Espírito Santo (20052010), the text aims to analyze the constitution of forms of resistance that problematize the power relations instituted nowadays. The act of land reclamation undertaken by these ethnic groups and the ensuing effects on the production and articulation of rebel actions are debated amid the fissures they have caused in the modes of political functioning that weave the state's administrative machine, as well as the social movements themselves. The emergence of dissident dynamics and fighting aesthetics is expressed in the confrontations between insurgency and counterinsurgency networks, serving as the analyzers of a world society of control spread throughout the social fabric.
\end{abstract}

Key-words: social movements; militancy; resistances.

DOI: $10.12957 /$ mnemosine.2020.57658 


\section{Introdução}

Este artigo apresenta um recorte das questões debatidas na dissertação de mestrado "Práticas de militância nômade: experimentações rebeldes e novas estéticas de luta no contemporâneo". Utilizando-se da experiência de um dos autores no processo de luta pela terra dos povos indígenas Tupinikim-Guarani no Estado do Espírito Santo, o texto objetiva analisar a constituição de formas de resistência problematizadoras das relações de poder instituídas na atualidade. $\mathrm{O}$ ato de retomada da terra empreendido por essas etnias e os efeitos que se seguiram na produção e articulação de ações rebeldes são debatidos em meio às fissuras que provocaram nos modos de funcionamento político que tecem a máquina administrativa do Estado, bem como dos próprios movimentos sociais. A emergência de dinâmicas e estéticas de luta dissidentes se expressa nos afrontamentos entre redes de insurgência e contra-insurgência, servindo como analisadores de uma sociedade mundial de controle espraiada por todo o tecido social.

\section{Narrativa de uma experiência}

Era maio de 2005, madrugada de uma segunda feira, dia 17. Aproximadamente 400 índios Tupinikim e Guarani, habitantes de seis aldeias no município de Aracruz, região norte do Espírito Santo, insurgem-se contra a morosidade do Estado Brasileiro no reconhecimento de seu território e deflagram o movimento de autodemarcação de 11.070 hectares de terras. Contestando o Estado em sua autoridade político-jurídica, delimitam a área física de seu território baseando-se em métricas estabelecidas por estudos da Fundação Nacional do Índio (FUNAI).

Após 80 quilômetros percorridos na rodovia ES-010 - estrada que margeia belas praias do litoral norte capixaba -, desviamos por uma estrada de barro, adentrando numa enorme plantação de eucalipto, até chegar à aldeia Tupinikim de Irajá, onde avistamos uma escola. $\mathrm{Na}$ frente da pequena casa de alvenaria reúnem-se em silêncio centenas de indígenas. Alguns estão pintados com grafismos de guerra, desenhados com a tinta vermelha do urucum e o preto do jenipapo. São homens e mulheres de todas as idades. Uns portam motosserras, outros facões, uns bordunas e tacapes, outros arcos e flechas. Muitas crianças e jovens circulam no local. O dia está ensolarado, céu azul. Não há medo nos olhares. Ao contrário, corpos orgulhosos expressam força e dignidade. 
Do outro lado da estrada de barro alguém a todos convoca. Indígenas e apoiadores recém-chegados se reúnem para uma conversa. Com calma e convicção falam os mais velhos, rememorando a história do seu povo, os embates já travados. Momento para acertar os últimos detalhes, sintonizando as orientações para o primeiro dia de trabalho. Alguns dedos apontam na direção dos monocultivos, mirando uma linha imaginária, buscando uma exatidão. Um momento de suspensão no tempo, como que indagando: "esse é o momento? Tomamos a história em nossas mãos?"

Obviamente sem respostas, no meio do mato adentramos. Descemos um terreno íngreme segurando em galhos de pequenas árvores e arbustos, até chegarmos adiante, nos primeiros eucaliptais, plantados numa disposição homogênea e disciplinada. De repente, um susto! O som estridente das motosserras sobressai e se impõe aos outros sentidos. Bastam alguns segundos até que as primeiras árvores caiam. O cruzamento de troncos em queda livre assemelha-se aos passos sincronizados de um balé. Gritos de euforia irrompem em meio ao ronco dos motores. Um sentimento coletivo de alegria, como num festejo, preenche nossos corpos. Medo e coragem se entrelaçam, produzindo a sensação de nos conectarmos a um fio rebelde da história.

Difícil imaginar beleza em árvores caindo... Parece reverberar certa dissonância com a vida. No entanto, não se trata de uma metáfora. Nessa circunstância, a queda do eucalipto se torna o símbolo mais evidente da reconquista do território. É, por isso, a afirmação mais clara e sensível para expressar a experiência estética, visual e política ali vivenciada. Há cerca de 40 anos o cotidiano desses povos é construído nos interstícios dessas imensas plantações, impondo ao seu redor um estado de privações. Até a década de 1970 (quando se utilizaram pela primeira vez da autodemarcação como expediente de luta), os Tupinikim viviam ilhados num enclave de apenas 40 hectares, sendo considerada etnia extinta pela historiografia oficial. Símbolo da arbitrariedade e da violência, o corte do eucalipto é, assim, a afirmação concreta do direito à vida e a autodeterminação.

O corte abre uma clareira de aproximadamente quatro metros de largura, por onde caminhamos. A retirada de duas fileiras paralelas de eucalipto talha um caminho retilíneo, efeito do cultivo da árvore em posições equidistantes, resultado da ordenação do espaço a partir de uma finalidade economicamente lucrativa. Ao longo do percurso, os mais velhos (re)constituem a memória de tempos idos para ouvidos atentos dos mais novos. A história de um povo (in)surgindo transmite-se no processo da luta, produzindo novos sentidos para/pelas novas gerações. 
O pajé guarani de nome Wera Tupã, da aldeia Boa Esperança, segue a multidão com passos largos e calmos, sem tocar numa única árvore. Fuma o seu petynguál e bafora fumaça por onde caminha. Parece-nos que apenas observa a situação. Ledo engano. Nas andanças pela trilha que se fende, nos conta: “o eucalipio é uma árvore venenosa! Não foi criada por Nhãnderu... ${ }^{2}$ É uma árvore sem espírito!”. Seu trabalho desenvolve-se numa outra dimensão, invisível aos nossos olhos. Baforando fumaça no ambiente e no próprio corpo, garante a proteção necessária para aqueles que desafiam as forças mundanas, travando batalhas no mundo espiritual.

À tarde, uma delegação do Movimento dos Pequenos Agricultores (MPA) se aproxima com bandeiras vermelhas. A cena é, no mínimo, inusitada. Homens e mulheres - brancas, loiras, de olhos azuis, com chapéus de palha e trajes camponeses descem dos ônibus com presentes que alimentarão aquele ato de rebeldia. Trazem suas produções agroecológicas (inhame, mandioca, batata doce, feijão, hortaliças), frutos da resistência que os conecta. Até serem recepcionados pelos seis caciques, passam por um "corredor" humano formado por guerreiros indígenas. Uma primeira impressão de hostilidade logo se dissipa com os cumprimentos e sorrisos que seguem. Ritualística que sela, mais uma vez na história de luta dessas comunidades, a aliança entre diferentes povos pela defesa e proteção de seus territórios e modos de vida.

\section{Pintados para a guerra}

Ainda que na iminência de uma reação da Polícia Federal, o processo de autodemarcação se estendeu ininterruptamente por quatro dias e uma noite. Discursos afinados com os interesses do mercado não tardaram a brotar, repudiando a "invasão" das terras, duvidando da "autenticidade" étnica dos manifestantes, condenando os "Atos de Violência Contra o Patrimônio e a Ordem Pública", prestando "Solidariedade Contra a Barbárie e a Desordem", conforme manchetes veiculadas à época nas mídias hegemônicas.

O conflito provocou e instituiu, por conseguinte, redes de solidariedade não somente aos Tupinikim-Guarani e antagonismos não somente à multinacional, evidenciando um complexo campo de batalha em que outros territórios - não somente o agrário - foram taticamente ocupados. À medida que as intervenções se multiplicavam e movimentos se constelavam, os abalos provocados no projeto da empresa obrigaram-na a deslocamentos que apontaram para estratégias e relações de poder espraiadas por todo 
o tecido social. Nesse cenário, emergiu uma intensa disputa por legitimidade, não somente da posse da terra, mas, principalmente, dos modos de dispor e usar a Vida.

Na capital do Espírito Santo (Vitória), em razão do boicote operado pela grande imprensa, um grupo de pessoas se reuniu para apoiar a luta. Paulatinamente essas pessoas constituíram um corpo coletivo denominado Brigada Indígena, exercitando uma função conectiva entre movimentos sociais do campo e da cidade. Operações de intercambio étnico e ações simultâneas nos territórios da urbis e da ruris fizeram ressoar a voz indígena em espaços ativamente organizados para silenciá-la. A abertura criativa, forçada e imprevisível desses espaços intensificou, visibilizou e incitou articulações difusas e estratégias de controle que visavam constituir o terreno social a partir da produção de consensos em torno de projetos e estilos de vida monoculturais.

Antes de partirmos para a análise dessas aberturas, no entanto, faz-se necessário desenhar o campo de emergência dessa luta e apresentar alguns dos processos que constituíram parte da gênese deste conflito pela terra. Façamos, então, um breve percurso pela "Terra Sem Males". 3

\section{Distendendo o arco}

Nos primórdios da colonização do solo brasileiro, os Tupinikim habitavam terras litorâneas hoje identificadas como Bahia, Rio de Janeiro, São Paulo e Paraná. Em decorrência dos conflitos e das doenças advindas do contato com o invasor, sua população foi drasticamente reduzida: no século XIX, a vastidão de terras antes habitada por esse povo restringia-se ao solo capixaba. Apertados nessa fronteira, os remanescentes Tupinikim buscaram refúgio no município de Aracruz, onde extensões territoriais encontravam-se ainda preservadas, possibilitando a prática dos seus modos de vida tradicionais. Aproximadamente trinta e sete aldeias distribuíam-se numa região de mata virgem, articulando-se e comunicando-se por trilhas no meio da floresta (SOUSA, 1996).

A partir de 1940, este cenário começou a modificar-se, quando a primeira grande empresa ali se instalou: a Companhia de Ferro e Aço de Vitória (COFAVI). Com autorização do Estado explorava cerca de 10.000 hectares de floresta para produção de carvão vegetal (SOUSA, 1996, p.14).

Em 1967 chega à região, vindo do Sul do país, um grupo de Guarani Mbyá, numa caminhada mítico-religiosa em busca da "Terra Sem Males". As condições 
geográficas e naturais, bem como a acolhida dos Tupinikim, foram determinantes para o seu estabelecimento naquele território.

No final da década de 60, a Empresa Aracruz Celulose iniciou seus empreendimentos no Espírito Santo, comprando os 10.000 hectares de terras da COFAVI e mais 30.000 hectares de terras habitadas pelos indígenas, negociadas pelo Estado por uma quantia irrisória. Intensificou-se, ali, o processo de expropriação que os obrigou a viver cada dia mais acuados. À medida que as matas eram derrubadas, as plantações de eucalipto se estendiam até o quintal de suas casas, deixando-os ilhados em nada mais que 40 hectares de terra.

Em 1975, essa situação foi denunciada nos maiores jornais do país, gerando uma pressão pública que forçou o governo a dar início aos primeiros processos administrativos de reconhecimento étnico. Mediante a mobilização e articulação com outros grupos sociais e a consequente pressão sobre o governo, em 1979 a FUNAI instalou um Grupo Técnico (GT), através da portaria $n^{\circ}$ 069/79, que decidiu, ao final dos estudos, pela delimitação de três aldeias. O presidente da Aracruz Celulose à época, entretanto, pressionou o governo, que recuou desta decisão. A empresa aproveitou o recuo para dar início a testes de plantação de eucalipto na área reconhecida pelos estudos da FUNAI como de uso ancestral indígena.

As lideranças indígenas à época escreveram uma carta ao Ministro do Interior e, em plena ditadura militar, prometeram delimitar suas terras caso o governo federal não o fizesse. Findo o prazo estipulado, realizaram a primeira autodemarcação que, ao longo das décadas seguintes, constituir-se-ia numa arma fundamental para a garantia da autonomia de seus modos de vida e a autoprodução de sua existência.

Vinte e seis anos após o reconhecimento oficial pelo Estado brasileiro, cerca de trezentos indígenas reunidos numa Assembleia Geral, no dia 19 de fevereiro de 2005, na aldeia de Comboios, decidem pela realização da terceira autodemarcação de sua história recente, como declarado em nota enviada ao presidente da FUNAI e à sociedade:

Na certeza da legitimidade e validade dos estudos do GT [da Funai] $e$ convencidos de que os 18.070 hectares de terras é direito dos povos Tupinikim e Guarani, tomamos a decisão de iniciar, no dia de hoje, a autodemarcação das nossas terras. Com este ato, queremos expressar para o Senhor, e para todo o povo brasileiro, que as terras pertencem aos povos Tupinikim e Guarani, e devem ser devolvidas para construirmos nosso próprio futuro, garantindo nossa liberdade e autonomia, e o futuro dos nossos filhos e netos. Quinhentos anos atrás cortaram as árvores que representam os povos e 
culturas indígenas: hoje, com nossa terra, voltam a brotar com força as raízes indígenas no Espírito Santo.

\section{A experiência do coletivo Brigada Indígena}

Um mês após o "início" do conflito, a Rede Alerta Contra o Deserto Verde ${ }^{4}$ realizou na Universidade Federal do Espírito Santo (UFES) um ciclo de debates sobre o processo de autodemarcação do território Tupinikim-Guarani. Nasce ali a primeira Brigada de Apoio aos Povos Indígenas.

O termo Brigada “(...) tem origem no italiano "brigat" (usado, por exemplo, na introdução do Decameron, onde se refere a um grupo de dez) ou no francês antigo brigare (significando "companhia" de tamanho indefinido), o qual, por sua vez, deriva da raíz celta briga, que significa "luta"'. 5 Denomina, comumente, uma formação grupal provisória organizada para o cumprimento de uma tarefa específica: brigada de incêndio; brigada de salvamento; brigada de segurança; etc. Como unidade tática, foi inventada pelo rei sueco Gustavo Adolfo, na Guerra dos Trinta Anos (século XVII), sendo considerada um protótipo organizacional da moderna "força-tarefa", criada pela marinha dos EUA no início de 1941 para designar forças navais temporárias e operacionalmente flexíveis, com grande capacidade de ação no cumprimento de missões eventuais. Por comportar uma elasticidade funcional, a ideia de brigada é empregada nas forças armadas da maioria dos países.

Fruto de uma ação específica (visita às aldeias), a Brigada Indígena não se constituiu a partir de uma pretensão organizativa estável ou permanente. Seu propósito não exigiu estruturas diretivas ou hierárquicas, regimentos, programas de ação ou cartas de princípio formalizadas. Modelou-se, isso sim, a partir de uma plasticidade operacional, adquirindo formas mutáveis e sensíveis às contingências situacionais. Suas ações eram realizadas simultânea ou assincronicamente no campo e na cidade, articuladas em redes de âmbito local, nacional e internacional. Não havia um centro de controle e tutela que concedia, conferia, outorgava ou formalizava a adesão de um membro ao grupo. O sentimento de pertencimento era co-fabricado, nunca heterodeclarado. Compunha a Brigada quem dela se sentisse parte: ninguém ou qualquer um.

As intervenções eram realizadas em eventos com grande potencial de visibilidade e comunicação com o público, interrompendo fluxos de informação hegemônica e produzindo fissuras nos domínios discursivos. Tais curtocircuitos 
provocavam estranhamentos nos ouvintes-espectadores, convocando-os a sentir, pensar e agir de maneiras divergentes ao estabelecido.

\section{Levantes e insurreições}

Anualmente, desde 1990, a Prefeitura Municipal de Vitória (PMV) realizava a Feira do Verde, evento de educação ambiental de maior representatividade coletiva da cidade e do Estado, do qual participava um público estimado em 200 mil pessoas. O objetivo deste evento, segundo a administração municipal, era promover uma reflexão sobre a sustentabilidade dos ecossistemas e das populações humanas. A feira mantinha atividades ao longo de uma semana, financiada com recursos públicos e da iniciativa privada.

As principais atrações concentravam-se em espaços organizados pelos patrocinadores mais abastados, tais como Aracruz Celulose (atual Fibria), Arcellor, Vale, Petrobrás, Samarco, entre outros. Seus enormes estandes destoavam dos das pequenas cooperativas e associações comunitárias. Formavam-se filas para a apreciação de seus espaços interativos e coloridos, equipados com alta tecnologia e ornamentados com materiais de primeira linha, empregados na simulação de biomas aquáticos e terrestres. Artistas desenvolviam atividades lúdicas relacionadas ao tema por meio da contação de estórias e teatro de bonecos, fabricando, assim, a simpatia de milhares de crianças advindas das escolas de todo o Espírito Santo, seu público prioritário.

Facilitadores ensinavam os espectadores a separar o lixo, economizar água e energia, reciclar, utilizando para isso o discurso de sustentabilidade das corporações que pagavam seus cachês. Os visitantes recebiam panfletos, cartilhas e brindes contendo informações sobre esses projetos, atestados por selos internacionais de certificação ambiental. Propagandas periódicas na mídia televisiva e impressa se encarregavam de reforçar uma imagem positiva dessas corporações, produzindo na população um sentimento de orgulho para com elas.

Tudo organizado de modo que a voz dos atingidos (pescadores, indígenas, quilombolas, sem terras, desabrigados, pequenos agricultores, carvoeiros, trabalhadores mutilados e envenenados, crianças com problemas respiratórios) não fosse ouvida e seus rastros apagados da história. Segundo Cecília Coimbra (2008),

A história que nos tem sido imposta seleciona e ordena os fatos segundo alguns critérios e interesses construindo, com isso, zonas de sombras, silêncios, esquecimentos, repressões e negações. A memória histórica "oficial" tem sido, 
portanto, um lado perverso de nossa história, produzida pelas práticas dos chamados "vencedores" no sentido de apagar os vestígios que os subalternizados e os opositores em geral vão deixando ao longo de suas experiências de resistência e luta. Essa história "oficial" tem construído desconhecimento sobre os embates ocorridos em nosso mundo globalizado, como se os opositores não estivessem presentes no cenário político (p. 109).

Durante os anos de 2005, 2006, 2007 e 2008, a Brigada Indígena ocupou essa feira buscando romper seu ordenamento oficial. Para isso, performou ações de cunho estético-político, provocando constrangimentos por meio de técnicas do escracho. Numa espécie de guerrilha simbólica, o coletivo irrompia contra uma determinística territorial asséptica e escrachava a aliança dos poderes instituídos que nesses espaços impunham, totalitariamente, uma monolítica unidade discursiva.

As intervenções visavam produzir um estranhamento do público para o que ali era imposto como único e verdadeiro e miravam, esquematicamente, dois de seus pilares: (1) o discurso oportunista das empresas (relativo às questões sócio-ambientais) e (2) a configuração de um espaço estatal de sustentação a esse discurso empresarial.

O primeiro pilar era atacado por meio de denúncias relativas aos impactos sócioambientais: poluição pelo pó de minério da Vale e seus impactos na saúde da população; destruição da Mata Atlântica para plantação de eucalipto; invasão de terras devolutas, campesinas, indígenas e quilombolas, inviabilizando a reforma agrária e provocando a expulsão de famílias do campo; exploração intensiva de mármore e granito e a não divulgação dos altos índices de acidentes e morte dos trabalhadores do setor; consumo exacerbado de água sem pagar nada por isso; desvio do Rio Doce para abastecimento da produção de celulose; desaparecimento de nascentes e vários pequenos rios e córregos; uso de produtos químicos sem respeito ao espaço mínimo exigido por lei entre as plantações e as nascentes etc.

Sempre que possível, viabilizava-se a vinda dos indígenas para a cidade, potencializando denúncias que rompiam o silêncio orquestrado em torno da luta pela terra, bem como produziam estranhamentos da população em relação às versões oficiais fabricadas pela empresa.

O segundo pilar era abalado por meio do questionamento da composição autoritária do espaço da Feira, organizada de modo a impedir a presença de sujeitos e ideias dissonantes aos interesses político-econômicos articulados entre empresas e governo. Desde 2002, por exemplo, a Aracruz Celulose figurava na lista das 25 empresas que mais realizavam doações em campanhas eleitorais no país. No Espírito 
Santo, a empresa ocupava a liderança nesse tipo de ranking, tanto nas eleições para o executivo quanto para o legislativo. Para ter uma dimensão desse alcance, em 2012, dos 36 candidatos a prefeito que apoiou diretamente, 16 se elegeram.

\section{Redes insurgentes e as novas morfologias rebeldes}

Antonio Negri e Michael Hardt (2005) afirmam, ao contemplar a genealogia das modernas revoltas e revoluções, que existe uma tendência mundial para a criação de organizações cada vez mais democráticas - divorciadas das formas centralizadas de comando -, nas quais a figura de autoridade é dissolvida e deslocada para relações colaborativas (p.15). Essas novas organizações revelam um modo de funcionamento que não as constitui somente como meio para o alcance de uma sociedade democrática, mas como fim dessa mesma sociedade que se almeja. Estudando as alterações morfológicas das modernas organizações rebeldes, os autores identificam transformações que expressam, a cada tempo, um desejo por revoluções mais democráticas, motor tanto da emergência quanto da imergência dessas diferentes formas organizativas.

Utilizando-se de exemplos históricos clássicos que envolvem, por exemplo, o exército popular da primeira metade do século $\mathrm{XX}$ e os grupos guerrilheiros da década de 1960 em diante, os autores discutem que tais organizações nem sempre conduziram a resultados políticos desejáveis, ainda que tenham sido militarmente eficazes no combate aos regimes ditatoriais que as precederam e que tenham proporcionado mudanças significativas em relação aos mesmos. Essas formas hierarquizadas, afirmam, não atenderam plenamente o desejo de democracia que os propulsou, apontando para um elemento politicamente indesejável sobre os quais identificamos, atualmente, o "calcanhar de Aquiles" de muitos movimentos sociais: o ressurgimento perseverante de um controle central e hierárquico no seio das próprias organizações.

Negri e Hardt (2005) atribuem esse ressurgimento constante a uma noção que fundamenta a autoridade tanto do Estado nacional quanto dessas organizações: o conceito de "povo". De acordo com os autores, essa categoria está intimamente vinculada à noção de soberania, tendendo a privilegiar centros de comando em detrimento da população como um todo. "A população, como se sabe, é caracterizada pelas mais amplas diferenças, mas o povo reduz essa diversidade a uma unidade" (p. 12). O "povo" é, portanto, uma categoria de soberania que legitima o uso da violência tanto contra uma autoridade vigente de Estado, quanto contra a alteridade da população. 
Os autores encontram na genealogia dessas organizações três princípios que orientam suas mutações: (1) a oportunidade histórica, capaz de indicar qual a forma mais eficaz de combate a uma forma específica de poder; (2) a correspondência entre essas formas e os modelos dominantes de produção; (3) a tendência de cada nova forma destinar-se a atacar as qualidades antidemocráticas das formas anteriores (p.103).

Nesse sentido, o moderno exército popular - que transformou bandos guerrilheiros de camponeses armados, dispersos e irregulares, numa massa unificada sob um comando centralizado - corresponderia aos exércitos de operários industriais organizados nas fábricas. E o modelo policêntrico da guerrilha, por sua vez, corresponderia à transição da produção fordista para a produção pós-fordista, quando "as técnicas e as formas organizacionais da produção industrial transferiram-se para unidades de trabalho menores e mais móveis, assim como para estruturas de produção mais flexíveis" (p.120).

Após 1968, as redes de comunicação, cooperação e informação que caracterizam o arsenal tecnológico pós-fordista começam a influenciar e a mudar radicalmente os movimentos de resistência e libertação. A Internet, por exemplo, passa a ser utilizada não apenas como ferramenta de organização, mas como o próprio modelo organizativo: a ordenação em rede

[...] baseia-se na pluralidade contínua de seus elementos e redes de comunicação, de tal maneira que a redução a uma estrutura de comando centralizada e unificada é impossível. A forma policêntrica do modelo guerrilheiro evolui assim para uma forma em rede na qual não existe um centro, apenas uma pluralidade irredutivel de nodos em comunicação uns com os outros (HARDT, NEGRI, 2005: 120).

À medida que os grupos guerrilheiros migram do campo para a cidade, essa tendência se acentua e os movimentos colocam para si outros horizontes: não mais tanto a tomada do aparelho estatal, mas sim a transformação do espaço urbano, suas paisagens, suas relações sociais, raciais, étnicas, econômicas, culturais, de gênero, orientação sexual, etc. Paulatinamente o foco volta-se para a produção de novos modos de vida dentro da própria organização, por meio de ações inventivas e subversivas capazes de liberar Zonas Autônomas Temporárias (TAZ) ${ }^{6}$ de experimentação.

Já não se pode tomar o "povo" como base desses movimentos. Hardt e Negri (2005) falam de multidão:

a multidão, em contrapartida, é múltipla. A multidão é composta por inúmeras diferenças internas que nunca poderão ser reduzidas a uma unidade ou identidade única [...]. A multidão é uma multiplicidade de todas essas diferenças singulares. [...] o desafio apresentado pelo conceito de multidão consiste em fazer com que uma 
multiplicidade social seja capaz de se comunicar e agir em comum, ao mesmo tempo em que se mantém internamente diferente (pp. 12-13).

A rede multitudinária oferece uma imagem do funcionamento da Brigada, da Rede Alerta Contra o Deserto Verde e das experimentações morfológicas dos movimentos sociais contemporâneos.

Segundo Hardt e Negri (2005), este novo paradigma organizativo resulta do desenvolvimento progressivo de redes cada vez mais complexas. O exército popular, por exemplo, mantinha uma estrutura militar tradicional que poderia ser descrita como "uma rede em forma de eixo ou estrela, na qual todas as linhas de comunicação e comando se irradiam de um ponto central em direções fixas" (p. 88). Já a guerrilha pode ser descrita como uma "rede policêntrica, com numerosos aglomerados centralizados e relativamente autônomos" (p. 88), se assemelhando a uma alcateia, capaz de agir independentemente ou em coordenação.

Da perspectiva da contra-insurgência, para cada uma dessas formas organizativas criou-se uma técnica específica de extermínio ou controle. No caso do exército popular, essa técnica consiste em eliminar o centro de onde se irradiam todas as linhas de comunicação e comando. Identifica-se a liderança de um determinado movimento insurgente para eliminá-la, isolá-la ou prendê-la. No caso da guerrilha, o método consiste em destruir o ambiente físico e social que lhe dá sustentação.

Entretanto, à medida que os coletivos rebeldes adotam uma forma de organização em redes cada vez mais policêntricas, acêntricas, temporárias, com ambiente de apoio amplo e virtual, sem localização, a capacidade das técnicas contrainsurgentes veem-se reduzidas.

De uma perspectiva externa, o ataque em rede é apresentado como um enxame porque parece informe. Como a rede não tem um centro que determine a ordem, aqueles que só são capazes de pensar em termos de modelos tradicionais podem presumir que ela não tem qualquer forma de organização - o que eles enxergam é apenas espontaneidade e anarquia [...] uma multidão de atacantes irracionais, desconhecidos, incertos, invisíveis e inesperados. Se analisarmos o interior de uma rede, no entanto, veremos que é efetivamente organizada, racional e criativa (HARDT, NEGRI, 2005: 130-131).

A luta indígena pela terra baseou-se em "ataques" à multinacional da celulose articulados entre diversos atores e em diferentes escalas, fundamental para o enfrentamento de uma empresa com influência sobre amplos setores e segmentos políticos e sociais. As ações locais dos indígenas reverberaram por meio de manifestos, 
campanhas, informes, denúncias, abaixo-assinados, intervenções urbanas, debates, palestras, seminários, passeatas, protestos, marchas, ocupações e interdições de vias públicas promovidas por outros nodos dessa Rede, em iniciativas autônomas e articuladas que mobilizaram, por sua vez, novos grupos de apoio e/ou de pressão sobre o governo e a empresa, desencadeando sucessivas reações em cadeia. Como numa espiral promissora, cada nodo foi retroalimentado pelos demais, fortalecendo um modo de guerrilha do tipo enxame e um modo organizativo de tipo rede disseminada, apoiados numa movimentação multitudinária.

Nessa direção, o conflito se alastrou para além do espaço físico a que estava circunscrito, bem como das relações diretas a que estava submetido, trazendo para a cena atores que, aparentemente ausentes e/ou geograficamente distantes, teciam redes de suporte e de produção da realidade contra a qual os indígenas estavam a se rebelar.

\section{Redes contra-insurgentes: molecularizações fascistas}

À medida que o enxameamento das ações dos indígenas e de seus apoiadores furava consensos históricos em torno da empresa, esta modulou sua reação lançando-se estrategicamente sobre os efeitos disruptivos das intervenções operadas, num esforço contínuo para frear aberturas indesejáveis na resolução do conflito. Para remendar ao máximo uma legitimidade abalada, a Aracruz Celulose experimentou uma série de técnicas articuladas de contra-insurgência que objetivavam esvaziar a potência desestabilizadora daquelas forças rebeldes.

Segundo Foucault (1999), as resistências não estão numa posição de exterioridade em relação ao poder. Elas não são uma mera reação. Assim como o poder, elas encontram-se no campo das relações de força e, neste sentido, estão em cada ponto dessa correlação como um conjunto heterogêneo de práticas locais, pontuais, difusas e imprevisíveis, se distribuindo pelo tecido social de forma irregular e se disseminando como pontos móveis e transitórios. A resistência constitui uma experimentação inédita, inventiva, original, sobre a qual o poder se lança numa tentativa de contenção, desvio e/ou integração. Esse emaranhado de relações forma "um tecido espesso que atravessa os aparelhos e as instituições, sem se localizar exatamente neles (...).” (FOUCAULT, 1999: 92).

As reações da empresa evidenciam estratégias contemporâneas de contrainsurgência. Uma das características essenciais da rede disseminada, como já falamos, é 
o fato de não ter um centro e suas ações distribuírem-se de maneira variável, desigual e indefinida. Sua presença e ausência tendem a ser indeterminadas, configurando redes extremamente fugidias, efêmeras, invisíveis, com a habilidade de desaparecer instantaneamente no momento seguinte em que parecem universais (HARDT, NEGRI, 2005: 86). Para esse novo combate em rede, as técnicas de contra-insurgência são produtivas - mais refinadas e sutis -, criando e controlando sujeitos e ambiente, enfrentando os movimentos insurgentes não apenas em termos militares, mas políticos, econômicos, sociais, ideológicos e psicológicos. Como afirmam Hardt e Negri (2005): "só é possível combater uma rede com outra rede" (p. 90).

Desse modo, visando alcançar seus objetivos, a Aracruz Celulose fortaleceu sua presença em redes já bem constituídas: no legislativo e executivo, recebendo declarações de apoio; no judiciário, impetrando ações de criminalização dos militantes; na grande imprensa, pagando propagandas milionárias e obtendo de retorno matérias “jornalísticas” favoráveis.

Além de ativar e fortalecer essas malhas de apoio já existentes, a multinacional da celulose procurou estender seus tentáculos para recantos microscópicos da vida cotidiana da população aracruzense, formando, deliberadamente, redes de relações micropolíticas. ${ }^{7}$ Para tal empreendimento, apropriou-se de táticas historicamente construídas pelos movimentos sociais.

No intuito de garantir a posse das terras em disputa e interferir numa correlação de forças que se tornava cada dia mais desfavorável, espalhou medo e dúvidas na população. Disseminou-se pela cidade de Aracruz um temor generalizado em relação ao desemprego e a falência de pequenos negócios, produzindo efeitos de condescendência à empresa e de violência e racismo para com os indígenas, intencionalmente expostos como os responsáveis por uma tragédia social anunciada.

Com o apoio dessa malha, a atuação da empresa intensificou-se e se capilarizou por meio de: palestras em escolas públicas e privadas; promoção de projetos de educação ambiental, com visitas monitoradas à sua fábrica; financiamento de ONGs e instituições religiosas; tentativas de financiamento de pesquisas na UFES; oferta de recursos financeiros e materiais para a Associação Indígena Tupinikim-Guarani (AITG); produção e distribuição de cartilhas difamatórias em inúmeras empresas e estabelecimentos de ensino; distribuição de outdoors pela cidade de Aracruz; criação do "Movimento de Apoio a Aracruz Celulose", composto por sindicatos de trabalhadores e empresas diversas; promoção de passeatas nas cidades de Aracruz e Vitória; entrega de 
abaixo-assinado às autoridades políticas; publicação paga e orquestrada de notas de apoio nos principais jornais do ES.

A articulação de técnicas de "terror" em diferentes dimensões criou, portanto, um ambiente de hostilidade para com os indígenas, alimentando inúmeros eventos discriminatórios em seu cotidiano de vida: comerciantes locais se recusaram a venderlhes suas mercadorias (alimentos, materiais de limpeza, roupas, etc); crianças indígenas foram discriminadas nas escolas por estarem pintadas de acordo com seus costumes; olhares ofensivos e falas agressivas foram-lhes dirigidos nos espaços fora das aldeias.

$\mathrm{O}$ discurso oficial do Estado equalizou-se à voz de madeireiros, garimpeiros e latifundiários. O antropólogo Mércio Gomes Pereira, na época presidente da FUNAI (órgão criado, diga-se de passagem, a partir da retórica estatal de defesa e garantia dos direitos dos povos indígenas brasileiros), declarou à Agência de notícias Reuters, no dia 12 de janeiro de 2006, que esses povos brasileiros tinham terras demais: “Até agora, não há limites para suas reivindicações fundiárias, mas estamos chegando a um ponto em que o Supremo Tribunal Federal terá de definir um limite". ${ }^{8}$ Discurso que circulou na sociedade, nas mídias e nas ruas, reforçando uma engrenagem produtora de racismos, desigualdades e hierarquias sócio-culturais.

\section{Conclusão}

O conflito pela terra indígena Tupinikim-Guarani sublinha duas questões importantes sobre o modo de funcionamento do poder no contemporâneo. Primeiro, que não é possível entendê-lo apenas por sua função repressiva.

Para Foucault (1995), o poder não se refere a uma substância ou propriedade e, portanto, não pode ser adquirido, guardado, trocado. São correlações de força instáveis, tensas, desequilibradas, heterogêneas, móveis, desiguais e imanentes às redes sociais. Trata-se de um “[...] modo de ação que não age direta e imediatamente sobre os outros, mas que age sobre sua ação. Uma ação sobre a ação, sobre ações eventuais, ou atuais, futuras ou presentes." (FOUCAULT, 1995: 243). O poder é da ordem do "governo". Machado (2013) circunscreve assim a discussão de Foucault sobre o poder: "seu objetivo básico não é expulsar os homens da vida social, impedir o exercício de suas atividades, e sim gerir a vida dos homens, controlá-los em suas ações”, de modo a diminuir "sua capacidade de revolta, de resistência, de luta, de insurreição" (p. 20), tornando-os politicamente "dóceis". 
A segunda questão que o conflito expõe é que o poder já não fabrica os indivíduos apenas em espaços fechados. As reações da multinacional ressaltam técnicas de contra-insurgência a "céu aberto", articuladas no intuito de estriar a vida em todos os seus sentidos, de controlar espaços, paisagens, ideias, de modo que o pensamento seja determinado por um único ponto de vista, uma monocultura existencial.

Hardt (2000), ao examinar o mundo globalizado a partir de uma proposição de Deleuze (1992) sobre as sociedades contemporâneas, afirma que vivemos em uma sociedade mundial de controle marcada por novas formas de poder e novos mecanismos de produção de subjetividade, encarregados de fabricar formas de existência serializadas e de controlar os ambientes que as sustentam. Não há mais fronteiras rígidas, espaços fechados, Estados nacionais que impeçam os fluxos de informação, de comunicação, de relação e de afeto circularem. Por isso mesmo, tenta-se prender a vida por uma série de mecanismos co-modulados em redes flexíveis de microconflitualidades.

Se o conflito pela terra sublinha uma determinada leitura do poder, por conseguinte, ressalta importantes questões sobre os modos de resistência no contemporâneo. Como demonstrado ao longo do texto, a experiência da Brigada efetua uma análise das mutações morfológicas das modernas organizações revolucionárias.

Críticos ao modelo da esquerda institucionalizada e de suas estruturas piramidais de Partido e Vanguarda, esses coletivos rebeldes emergem de relações colaborativas e horizontalizadas, avessas às formas centralizadas de comando. De acordo com Acácio Augusto (2016), expressam "a afirmação de uma recusa radical, ética e estética, às formas de vida possíveis sob o domínio do capitalismo e do Estado” (p.12).

Suas ações apontam um paradigma de lutas organizadas em forma de rede (rede de redes, movimento de movimentos), que visam, dentre outros objetivos, ampliar os efeitos de assalto e defesa de seus levantes. Hardt e Negri (2005) afirmam que "quando uma rede disseminada ataca, investe sobre o inimigo como um enxame: inúmeras forças independentes parecem atacar de todas as direções num ponto específico, voltando em seguida a desaparecer no ambiente" (p.130-131). Elas podem ser temporárias, pequenas e localizadas, mas atingem uma rede difusa e globalizada de relações de poder.

São levantes que irrompem, também, não somente como reação a uma determinada ordem instituída, mas, principalmente, como afirmação de outros modos de vida. Experimentações rebeldes que não se limitam a oposições ou negações, mas que se multiplicam na invenção de diferentes modos de (re)existência em meio ao cultivo de monoculturas existenciais. Assim, as estéticas reticulares de (re)existência afirmam 
dinâmicas de luta e de modos de expressão da existência que são dissidentes aos modos hegemônicos de lutar, de existir, fabricando experimentações subversivas que não advogam perenidade ou sua reprodução e continuidade infinitamente; aparecem e desaparecem no tempo-espaço.

A experiência indígena ensina ao coletivo que a exclusiva submissão da luta a determinados procedimentos burocráticos e protocolos jurídicos restringe o campo de disputa a mecanismos estatais que podem impulsionar a interiorização dos movimentos em arenas afastadas do cotidiano, onde exercem sua soberania. Códigos frios, 'regras de etiqueta', filtros de conduta e jogos de poder tendem a ser efetivados por especialistas na arte da negociação (muitos cooptados no seio dos próprios movimentos), produzindo uma cena para a apreensão e canalização da revolta que produz como efeito a redução de sua potência. Nesses espaços estriados, esquadrinhados, esteticamente ordenados, restam poucas brechas para um movimento de ruptura com essa lógica instituída.

Desse modo, as intervenções, portanto, perdem sua potência ao agirem conforme esses regulamentos. Aqueles que se recusam a participar dessas arenas são apresentados como elementos perigosos, desgarrados, bárbaros, tentando-se cooptá-los, seduzi-los, desqualificá-los, marginalizá-los, criminalizá-los, reprimi-los e, se necessário for, exterminá-los. Porém o Estado não alcança aquilo que é pura velocidade. A imprevisibilidade da máquina de guerra e a invisibilidade da TAZ compõem uma poderosa estética de luta, capaz de afirmar outras formas de resistência. Inúmeros agrupamentos rebeldes, em diferentes tempos e espaços, utilizaram técnicas de invisibilidade em situações conflitivas com exércitos nacionais e/ou grupos mercenários semelhantes. Por exemplo, indígenas e quilombolas aproveitaram-se das densas florestas tropicais para realizar fugas repentinas e/ou ataques surpresas, visando a defesa de seus territórios.

Não pretendemos neste artigo discutir a experiência da Brigada como um modelo, um ideal de ação ou de organização. Queremos, sim, afirmar seu caráter experimental e provisório. Trata-se de uma invenção datada e localizada que interroga os modos institucionalizados de resistir. Assim como ela, outras experimentações em Vitória, no Espírito Santo, no Brasil e no mundo compõem o anúncio de um novo ciclo de revoltas, com estéticas e dinâmicas emergentes de luta. São "coletivos”, "grupos”, "redes", "fóruns", "frentes" que, apesar de origens distintas e ações diversas, emergem de críticas compartilhadas ao modelo da esquerda institucionalizada e suas estruturas piramidais de Partido e Vanguarda. 
Ao analisar a experiência da luta indígena, evidencia-se o potencial subversivo dessa estética reticular de (re)existência, capaz de forçar o Estado brasileiro a homologar o território Tupinikim-Guarani no ano de 2010. São estéticas que assombram o governo da existência, fazendo, por vezes, a máquina estatal engasgar.

\section{Referências}

AUGUSTO, A. Antipolítica e nova política: o movimento antiglobalização, anarquia e os governos do Sul. I Congreso de Investigadorxs sobre anarquismo, $\mathrm{n}^{\mathrm{o}} 1$, 2016, Buenos Aires. Disponível em: <https://www.academia.edu/31969725/Antipol\%C3\%AD tica_e_nova_pol\%C3\%ADtica_o_movimento_antiglobaliza\%C3\%A7\%C3\%A3 o_anarquia_e_os_governos_do_Sul>.Acesso em: 05 set. 2020.

ÀS Claras 2012. Trasparência Brasil. Disponível em: $<$ http://www.asclaras.org.br/@ doador.php?cargo=1\&partido=\&municipio=1\&es tado $=7 \&$ cargo_nome $=\&$ partido_nome $=\&$ estado_nome $=E s p \% E D r i t o+S a n t o \& m$ $\underline{\text { unicipio_nome }=\& a n o=2012 \& \text { doador }=3466361}$ > . Acesso em: 22 dez. 2019.

BRANDÃO, C. R. Os Guarani: índios do Sul - religião, resistência e adaptação. Estud. av. São Paulo, v. 4, n. 10, p. 53-90, Dec. 1990.

BRASIL. Constituição (1988). Constituição da República Federativa do Brasil. Brasília, DF: Senado, 2003.

BEY, H. TAZ: zona autônoma temporária. São Paulo: Conrad Editora do Brasil, 2011.

COIMBRA, C. Estratégias de resistência e criação: ontem, hoje. In: GUARESCHI, N. (org.). Estratégias de invenção do presente: a psicologia social no contemporâneo. Rio de Janeiro: Centro Edelstein de Pesquisas Sociais, 2008.

DELEUZE, G; GUATTARI, F. Mil Platôs: capitalismo e esquizofrenia, vol. 3. São Paulo: Ed. 34, 1996.

DELEUZE, G. (1972-1990). Post scriptum sobre as sociedades de controle. In: DELEUZE, G. Conversações. Trad. Peter Pál Pelbart. 34 ed. São Paulo, SP: Editora 34, 1992, p. 219-226.

FOUCAULT, M. O sujeito e o poder. In: DREYFUS, H.; RABINOW, P. Michel Foucault, uma trajetória Filosófica. Rio de Janeiro: Forense Universitária, 1995.

FOUCAULT, M. História da sexualidade I: a vontade de saber. Rio de Janeiro: Graal, 1999. . Microfísica do poder. Rio de Janeiro: Graal, 2013.

HARDT, M. A sociedade mundial de controle. In: ALLIEZ, E. (Org.). Gilles Deleuze: uma vida filosófica. São Paulo: Editora 34, 2000.

HARDT, N.; NEGRI, A. Multidão. Rio de Janeiro: Record, 2005.

MACHADO, R. Introdução: por uma genealogia do poder. In: Microfísica do poder. Rio de Janeiro: Graal, 2013. 
PAITER Surui. Manifesto Contra Declarações do Presidente da Funai Mercio Gomes que Propõe Limitar o Direito dos Povos Indígenas do Brasil. Disponível em: $<$ http://www.paiter.org/manifesto-contra-declaracoes-do-presidente-da-funaimercio-gomes-que-propoe-limitar-o-direito-territorial-dos-povos-indigenas-dobrasil/>. Acesso em: 22 dez. 2019.

SOUSA, J. R. C. de. TUPINIKIM E GUARANI. Comissão de articulação. (CIMI). Campanha internacional pela ampliação e demarcação das terras indígenas Tupinikim e Guarani. Aracruz, 1996.

WIKIPÉDIA. Brigada. Disponível em:〈http://pt.wikipedia.org/wiki/Brigada>. Acesso em: 22 dez. 2019.

Fernando Pinheiro Schubert - UFES

E-mail: fernandopinheiroschubert@gmail.com

Ana Lúcia Coelho Heckert - UFES

\footnotetext{
${ }^{1}$ A palavra guarani para "cachimbo" é petynguá e o termo tupi para tabaco é petyma, o que originou o verbo em português "pitar", que significa "fumar".

${ }^{2}$ Figura primária na maioria das lendas guaranis. É o deus trovão, realizador de toda criação. Também conhecido como Iamandu ou Tupã.

${ }^{3}$ Entre os Guarani subsiste a ideia e o desejo coletivo da busca da "Terra Sem Mal", esperança sobre a qual, para alguns estudiosos, está fundada sua religião: "A Terra sem Males não é apenas um lugar para onde a tribo deve se deslocar sem tréguas em busca de uma vida sem a morte e sem o mal. Ela é também um tempo, pois eis que pelo menos entre os Guarani atuais um cataclismo próximo que, diferente de um primeiro, ancestral, destruirá a Terra má de agora e somente serão salvos os que houverem se posto em marcha em busca da Terra Sem Mal.” (BRANDÃO, 1990: 63).
}

${ }^{4}$ A Rede Alerta contra o Deserto Verde é uma ampla rede da sociedade civil, composta de entidades, movimentos, comunidades locais, sindicatos, igrejas e cidadãos de cinco estados brasileiros (ES, MG, BA, RS e RJ) preocupados com os impactos socioambientais provocados pela contínua expansão das monoculturas de eucalipto. Ao mesmo tempo em que denuncia, mostra a viabilidade de alternativas de desenvolvimento que têm sido implementadas localmente por vários movimentos e comunidades que participam da Rede. O termo Deserto Verde foi cunhado por Augusto Ruschi - patrono da ecologia no Brasil e um dos ícones mundiais da proteção ao meio ambiente - para descrever uma paisagem que, embora "verde", elimina a diversidade biológica e humana que antes existia na Mata Atlântica.

${ }^{5}$ Disponível em: <http://pt.wikipedia.org/wiki/Brigada>. Acesso em: 22 dez. 2019.

${ }^{6}$ Termo proposto pelo anarquista Hakim Bey, no livro TAZ - Zona Autônoma Temporária.

7 Deleuze e Guattari (1996) afirmam que "tudo é político, mas toda política é ao mesmo tempo macropolítica e micropolítica" (p. 90). A macropolítica se refere a uma linha de segmentaridade dura ou molar que coloca em jogo conjuntos ou elementos bem determinados (Estado e sociedade civil, burguesia e proletariado, homens e mulheres, índios e brancos, crianças e adultos, etc). A micropolítica se refere a uma linha de segmentação maleável ou molecular concernente a fluxos que escapam dessas formas. Essas linhas participam de um regime coextensivo, no qual as relações de força, engendramentos e produções (plano micropolítico) não se encontram em relação de oposição com as organizações de poder (plano macropolítico). A questão micropolítica diz respeito à formação dos desejos no campo social.

8 Disponível em: <http://www.paiter.org/manifesto-contra-declaracoes-do-presidente-da-funai-merciogomes-que-propoe-limitar-o-direito-territorial-dos-povos-indigenas-do-brasil/>. Acesso em: 22 dez. 2019. 